American Journal of Applied Sciences 7 (5): 702-710, 2010

ISSN 1546-9239

(C) 2010Science Publications

\title{
How to Find Wave-Scattering Parameters from the Causal Bond Graph Model of a High Frequency Filter
}

\author{
${ }^{1}$ Hichem Taghouti and ${ }^{1,2}$ Abdelkader Mami \\ ${ }^{1}$ Laboratory of Analysis and Commands Systems, Department of Electrical Engineering, \\ National Engineering School of Tunis, Box 37, 1002 Tunis Belvedere Tunisia \\ ${ }^{2}$ Electronic Laboratory, Department of Physics, Faculty of Sciences of Tunis, \\ 2092 El Manar Tunisia
}

\begin{abstract}
Problem statement: The aim of this study is to use the bond graph technique and the wavescattering formalism, jointly, to determine the scattering matrix of a high frequency filter with cut-off frequency $10 \mathrm{GHz}$. Approach: The first step consist to model the high frequency filter by bond graph approach, afterward, we decomposed the obtained causal bond graph model under an elementary structures of a cascaded sub-model, where, each one containing only 0 -junction (parallel admittance) and 1-junction (series impedance). The causal ways and algebraic loops present in each causal bond graph sub-model, allows us to derive the elementary wave matrix $\mathrm{W}^{(\mathrm{i})}$ of each sub-model. Results: The total or global wave matrix $\mathrm{W}^{(\mathrm{T})}$ of the high frequency filter is given by the product of all elementary wave matrixes $\mathrm{W}^{(\mathrm{i})}$. Conclusion: The scattering matrix $\mathrm{S}$ of the studied filter can be inferred by use of the founded wave matrix $\mathrm{W}^{(\mathrm{T})}$ which relates the incident and reflected waves at one port directly to the incident and reflected waves at the adjacent port and the relations linking the $\mathrm{S}$ coefficients to the $\mathrm{W}$ coefficients. Finally, the scattering parameters, founded from the wave matrix, will be checked by comparison of the simulation results.
\end{abstract}

Key words: Wave matrix, scattering parameters, bond graph modeling, low-pass filter

\section{INTRODUCTION}

The wave-scattering formalism (Paynter and Busch-Vishniac, 1988) has received great attention in microwave domain (Vendelin et al., 2005) and its application to low or high frequency circuits. The use of this scattering formalism, which intrinsically deals with causal relations and can explicitly include conservation laws, was advocated by Paynter (1992) as an alternative method for physical systems modeling. The major advantage of the wave-scattering approach is that unlike the conventional circuit approach, it affords a uniform treatment of dynamic elements and their interconnections, whatever their structure is.

Moreover, bond graph (Di Filippo et al., 2002) appears now as a powerful tool for modeling and analysis of dynamical system, traditionally used to describe continuous-time physical processes with a fixed structure (Cellier, 1995).

The propose of this study is to present and apply a new method to derive the scattering parameters of a high frequency filter from its causal and reduced bond graph model (Taghouti and Mami, 2009).
We propose to use the causal bond graph model of a high frequency filter based on localized elements (Trabelsi et al., 2003) to find the integro-differentials operators (Khachatryan and Khachatryan, 2008) which based on the causal ways and algebraic loops present in the causal bond graph model and, on the other side, to extract the wave matrix (Magnusson et al., 2001) from these operators. Then, we extract directly the scattering parameters (Newton, 2002) from the found wave matrix (Magnusson et al., 2001) by basing on the relations linking the $\mathrm{S}$ coefficients to the $\mathrm{W}$ coefficients.

Finally, at the aim to validate the found results; we make a comparison by the simulation of these scattering parameters under a simple program and under the classic techniques of conception and simulation of the microwave circuits by using the HP-ADS software (Vendelin et al., 2005).

Presentation of the new derivation method: The new derivation method of the scattering parameters (Paynter, 1992) is an analytical method which makes it possible to establish, for any linear complex system, the scattering relations between a fixed entry and exit.

Corresponding Author: Hichem Taghouti, Laboratory of Analysis and Commands Systems, Department of Electrical Engineering, National Engineering School of Tunis, Box 37, 1002 Tunis Belvedere Tunisia Tel: + 21699977532 


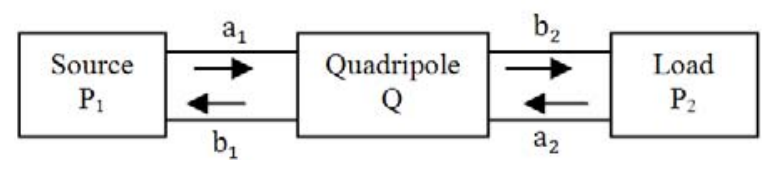

Fig. 1: Physical system representation

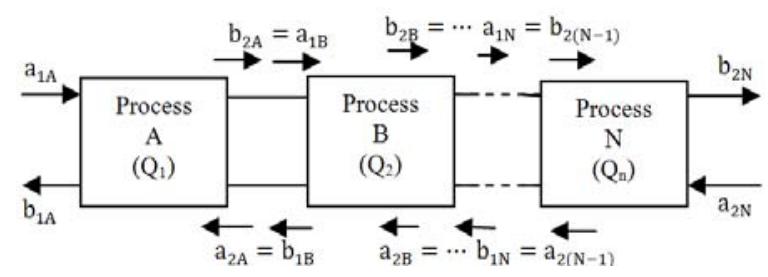

Fig. 2: Quadrupled decomposition and wave scattering representation

However, this method implies the succession of the following stages:

- Decomposition of the causal bond graph model to sub-models put in cascades, containing each one only 0 -junction and 1 -junction and which are characterized by their respective wave matrix (Magnusson et al., 2001)

- Calculating the total wave matrix of the whole system by carrying out the product of the elementary wave matrixes

- Finally, the application of a linear transformation to this total matrix give us the scattering parameters (scattering matrix) (Paynter, 1992) characterizing the complex system

The step that we propose was thought in this objective and consists in establishing a systematic method which binds the bond graph technique (Di Filippo et al., 2002) to the wave-scattering formalism (Paynter and Busch-Vishniac, 1988).

This method is based on an algebro-graphic procedure (Maher and Scavarda, 1991) which uses the causal ways notions and the Mason's rule applied to a causal bond graph transformed and reduced (Taghouti and Mami, 2009).

Physical system modeling with wave-scattering variables: We note that any physical complex system can be model like three subsystems (source, Quadripole (Q) and load) inter-connected and communicate between them by the means of a power transfer which is done in a continuous way from the source to the load as Fig. 1 indicates it.

It is considered that the quadripole is in complex form and can be decomposed to subsystems which are connected by the intermediary of the wave-scattering variables (Paynter and Busch-Vishniac, 1988) as Fig. 2 indicates it.

Let us consider the two processes $\mathrm{A}$ and $\mathrm{B}$ with share where the signal entering $\mathrm{B}$ is directed in the same direction as the outgoing signal of process A, a similar way, the outgoing signal of $\mathrm{B}$ is in the same direction as the signal entering A as Fig. 2 indicates it.

If these two processes are coupled, the assumption of the power continuity (Paynter and Busch-Vishniac, 1988) will imply:

$$
\begin{aligned}
& \mathrm{a}_{2 \mathrm{~A}}=\mathrm{b}_{1 \mathrm{~B}} \\
& \mathrm{~b}_{2 \mathrm{~A}}=\mathrm{a}_{1 \mathrm{~B}}
\end{aligned}
$$

The $a_{i A}$ and $a_{i B}$ quantities entering the $A$ and $B$ processes are called incident waves in the same way, the quantities $b_{i A}$ and $b_{i B}$ associated with the signals leaving the $\mathrm{A}$ and $\mathrm{B}$ processes are called reflected waves (Duclos and Clement, 2003).

Classically, we express the power circulating in a bond and connecting two systems in the shape of a product of the two variables effort (noted:c) and flow (noted : $\varphi$ ) in reduced form (Maher and Scavarda, 1991).

$$
\mathrm{P}=\left(\frac{\mathrm{a}_{\mathrm{i}}}{\sqrt{2}}\right)^{2}-\left(\frac{\mathrm{b}_{\mathrm{i}}}{\sqrt{2}}\right)=\varepsilon_{\mathrm{i}}, \varphi_{\mathrm{i}}
$$

$\left(\frac{a_{i}+b_{i}}{\sqrt{2}}\right)\left(\frac{a_{i}+b_{i}}{\sqrt{2}}\right)=\varepsilon_{i}, \varphi_{i}$

So we can introduce the following linear transformation:

$$
\left[\begin{array}{l}
\varepsilon_{\mathrm{i}} \\
\varphi_{\mathrm{i}}
\end{array}\right]=\frac{1}{\sqrt{2}}\left[\begin{array}{cc}
1 & 1 \\
1 & -1
\end{array}\right]\left[\begin{array}{l}
\mathrm{a}_{\mathrm{i}} \\
\mathrm{b}_{\mathrm{i}}
\end{array}\right]=\mathrm{H}\left[\begin{array}{l}
\mathrm{a}_{\mathrm{i}} \\
\mathrm{b}_{\mathrm{i}}
\end{array}\right]
$$

The linear opposite transformation of the $\mathrm{H}$ transformation allows the passage of the intrinsic variables effort and flows $(\varepsilon, \varphi)$ with the wave variables $\left(a_{i}, b_{i}\right)$ as the following relation indicates it:

$$
\left[\begin{array}{l}
\mathrm{a}_{\mathrm{i}} \\
\mathrm{b}_{\mathrm{i}}
\end{array}\right]=\frac{1}{\sqrt{2}}\left[\begin{array}{cc}
1 & 1 \\
1 & -1
\end{array}\right]\left[\begin{array}{l}
\varepsilon_{\mathrm{i}} \\
\varphi_{\mathrm{i}}
\end{array}\right]=\mathrm{H}\left[\begin{array}{l}
\varepsilon_{\mathrm{i}} \\
\varphi_{\mathrm{i}}
\end{array}\right]
$$

The processes A and B constitute two processes with 2-ports of entry and exit whose wave matrixes are:

$$
\left[\begin{array}{c}
\mathrm{b}_{1}^{\mathrm{A}} \\
\mathrm{a}_{1}^{\mathrm{A}}
\end{array}\right]=\left[\begin{array}{ll}
\mathrm{w}_{11}^{\mathrm{A}} & \mathrm{w}_{12}^{\mathrm{A}} \\
\mathrm{w}_{12}^{\mathrm{A}} & \mathrm{w}_{22}^{\mathrm{A}}
\end{array}\right]\left[\begin{array}{l}
\mathrm{a}_{2}^{\mathrm{A}} \\
\mathrm{b}_{2}^{\mathrm{A}}
\end{array}\right]
$$


Am. J. Applied Sci., 7 (5): 702-710, 2010

$\left[\begin{array}{c}\mathrm{b}_{1}^{\mathrm{B}} \\ \mathrm{a}_{1}^{\mathrm{B}}\end{array}\right]=\left[\begin{array}{ll}\mathrm{w}_{11}^{\mathrm{B}} & \mathrm{w}_{12}^{\mathrm{B}} \\ \mathrm{w}_{12}^{\mathrm{B}} & \mathrm{w}_{22}^{\mathrm{B}}\end{array}\right]\left[\begin{array}{l}\mathrm{a}_{2}^{\mathrm{B}} \\ \mathrm{b}_{2}^{\mathrm{B}}\end{array}\right]$

The chain of $n$ processes with 2-ports of entry and exit constitutes a process with 2-ports of entry and exit where the global wave matrix $\mathrm{W}$ is:

$$
\begin{aligned}
& \mathrm{W}=\mathrm{W}^{(\mathrm{A})} * \mathrm{~W}^{(\mathrm{B})} * \ldots \ldots . . * \mathrm{~W}^{(\mathrm{N})}=\prod_{\mathrm{i}=1}^{\mathrm{N}} \mathrm{W}^{(\mathrm{i})} \\
& {\left[\begin{array}{l}
\mathrm{b}_{1} \\
\mathrm{a}_{1}
\end{array}\right]=\left[\begin{array}{ll}
\mathrm{w}_{11} & \mathrm{w}_{12} \\
\mathrm{w}_{12} & \mathrm{w}_{22}
\end{array}\right]\left[\begin{array}{l}
\mathrm{a}_{2} \\
\mathrm{~b}_{21}
\end{array}\right]=[\mathrm{W}]\left[\begin{array}{l}
\mathrm{a}_{2} \\
\mathrm{~b}_{2}
\end{array}\right]}
\end{aligned}
$$

The scattering parameters are given by the following scattering matrix:

$$
\left[\begin{array}{l}
b_{1} \\
b_{2}
\end{array}\right]=\left[\begin{array}{ll}
S_{11} & S_{12} \\
S_{21} & S_{22}
\end{array}\right]\left[\begin{array}{l}
a_{1} \\
b_{2}
\end{array}\right]=[S]\left[\begin{array}{c}
a_{2} \\
a_{2}
\end{array}\right]
$$

The relations between these matrixes are given by these following equations:

$$
\left\{\begin{array}{c}
\mathrm{w}_{11}=-\mathrm{S}_{21}^{-1} * \mathrm{~S}_{22} \\
\mathrm{~W}_{12}=\mathrm{S}_{21}^{-1} \\
\mathrm{~W}_{21}=\mathrm{S}_{12}-\mathrm{S}_{11} * \mathrm{~S}_{22} * \mathrm{~S}_{21}^{-1} \\
\mathrm{~W}_{22}=\mathrm{S}_{11} * \mathrm{~S}_{21}^{-1}
\end{array}\right.
$$

And:

$$
\left\{\begin{array}{l}
\mathrm{S}_{11}=-\mathrm{W}_{22}^{-1} * \mathrm{~W}_{12} \\
\mathrm{~S}_{21}=\mathrm{W}_{22}^{-1} \\
\mathrm{~S}_{12}=\mathrm{W}_{11}-\mathrm{W}_{21} * \mathrm{~W}_{12} * \mathrm{~W}_{22}^{-1} \\
\mathrm{~S}_{22}=\mathrm{W}_{21} * \mathrm{~W}_{22}^{-1}
\end{array}\right.
$$

Wave-scattering variables and bond graph modeling of physical system: It is considered that the process, in its quadruple form and which inserted between two particular ports $\mathrm{P}_{1}$ and $\mathrm{P}_{2}$ which represent respectively the entry (source) and the exit (load) of the complex system can be represented by the following bond graph model transformed and reduced such us:

$\varepsilon_{1}$ and $\varepsilon_{2}=$ respectively the reduced variable (effort) at the entry and the exit of the system.

$\varphi_{1}$ and $\varphi_{2}=$ respectively the reduced variable (flow) at the entry and the exit of the system:

$$
\varepsilon_{\mathrm{i}}=\frac{\text { effert }}{\sqrt{\mathrm{R}_{0}}}
$$

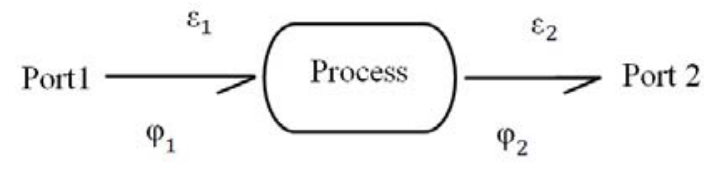

Fig. 3: The reduced bond graph representation

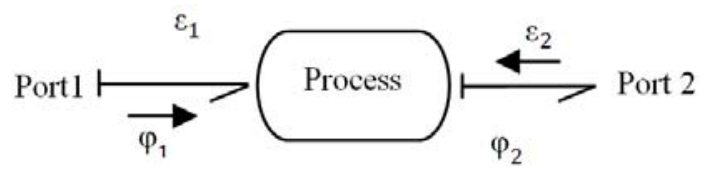

Fig. 4: Reduced bond graph model with flow-effort causality

$$
\varphi_{\mathrm{i}}=\text { flow } * \sqrt{\mathrm{R}_{0}}
$$

These are the reduced effort (e) and flow (f) with respect to $\mathrm{R}_{0}$ (scaling resistance).

And to establish the output-input analytical relations, the bond graph model of the studied system must be transformed, reduced and especially be causal since these relations rest on the concepts of causal way and causal algebraic loops which can comprise the reduced bond graph model.

The causality assignment to the reduced bond graph model of Fig. 3 enables us to notice that they are four different cases of causality assignment in inputoutput of the process (Maher and Scavarda, 1991).

For each type of reduced and causal bond graph model given below, we will have one matrix which connects the reduced wave-scattering variables to the integro-differentials operators $\mathrm{H}_{\mathrm{ij}}$.

From each matrix, we can deduce the corresponding wave matrix by referring to the Eq. 5, 6 and 10 .

These wave matrices can give us the corresponding scattering parameters by referring to the Eq. 13 and the following equations:

$$
\begin{aligned}
& {\left[\begin{array}{c}
\varepsilon_{1} \\
\varphi_{1}
\end{array}\right]=\frac{1}{\sqrt{2}}\left[\begin{array}{cc}
1 & 1 \\
1 & -1
\end{array}\right]\left[\begin{array}{l}
\mathrm{a}_{1} \\
\mathrm{~b}_{1}
\end{array}\right]} \\
& {\left[\begin{array}{c}
\varepsilon_{2} \\
-\varphi_{2}
\end{array}\right]=\frac{1}{\sqrt{2}}\left[\begin{array}{cc}
1 & 1 \\
1 & -1
\end{array}\right]\left[\begin{array}{l}
\mathrm{a}_{2} \\
\mathrm{~b}_{2}
\end{array}\right]}
\end{aligned}
$$

Case 1: (Flow-effort causality): From Fig. 4 and by referring to Eq. 13, 16 and 17, we can deduce the following integro-differential operators and the corresponding wave matrix:

$$
\left(\begin{array}{l}
\varepsilon_{1} \\
\varphi_{2}
\end{array}\right)=\left(\begin{array}{ll}
\mathrm{H}_{11} & \mathrm{H}_{12} \\
\mathrm{H}_{21} & \mathrm{H}_{22}
\end{array}\right)\left(\begin{array}{l}
\varphi_{1} \\
\varepsilon_{2}
\end{array}\right)
$$


Am. J. Applied Sci., 7 (5): 702-710, 2010

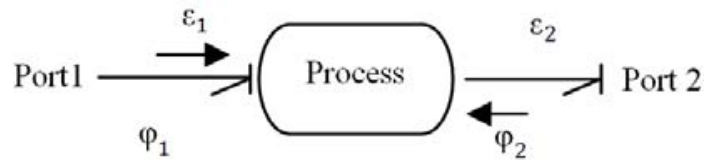

Fig. 5: Reduced bond graph model with effort-flow causality

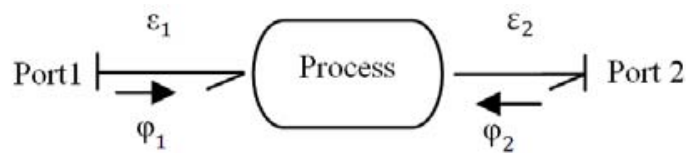

Fig. 6: Reduced bond graph model with flow-flow causality

$$
\begin{gathered}
\mathrm{W}=\left[\begin{array}{cc}
\frac{1-\mathrm{H}_{11}+\mathrm{H}_{22}-\Delta \mathrm{H}}{2 \mathrm{H}_{21}} & \frac{-1-\mathrm{H}_{11}+\mathrm{H}_{22}-\Delta \mathrm{H}}{2 \mathrm{H}_{21}} \\
\frac{-1-\mathrm{H}_{11}+\mathrm{H}_{22}-\Delta \mathrm{H}}{2 \mathrm{H}_{21}} & \frac{1-\mathrm{H}_{11}+\mathrm{H}_{22}-\Delta \mathrm{H}}{2 \mathrm{H}_{21}}
\end{array}\right] \\
\Delta \mathrm{H}=\mathrm{H}_{11}+\mathrm{H}_{22}-\mathrm{H}_{12} \mathrm{H}_{21}
\end{gathered}
$$

Case 2: (Effort-flow causality): From Fig. 5 and by referring to Eq. 13, 16 and 17, we can deduce the following integro-differential operators and the corresponding wave matrix:

$$
\begin{aligned}
\left(\begin{array}{l}
\varphi_{1} \\
\varepsilon_{2}
\end{array}\right) & =\left(\begin{array}{ll}
\mathrm{H}_{11} & \mathrm{H}_{12} \\
\mathrm{H}_{21} & \mathrm{H}_{22}
\end{array}\right)\left(\begin{array}{l}
\varepsilon_{1} \\
\varphi_{2}
\end{array}\right) \\
\mathrm{W} & =\left[\begin{array}{ll}
\frac{1-\mathrm{H}_{11}+\mathrm{H}_{22}-\Delta \mathrm{H}}{2 \mathrm{H}_{21}} & \frac{1-\mathrm{H}_{11}-\mathrm{H}_{22}+\Delta \mathrm{H}}{2 \mathrm{H}_{21}} \\
\frac{-1+\mathrm{H}_{11}+\mathrm{H}_{22}-\Delta \mathrm{H}}{2 \mathrm{H}_{21}} & \frac{1+\mathrm{H}_{11}-\mathrm{H}_{22}-\Delta \mathrm{H}}{2 \mathrm{H}_{21}}
\end{array}\right]
\end{aligned}
$$

Case 3: (Flow-flow causality): From Fig. 6 and by referring to Eq. 13, 16 and 17, we can deduce the following integro-differential operators and the corresponding wave matrix:

$$
\begin{aligned}
\left(\begin{array}{l}
\varepsilon_{1} \\
\varepsilon_{2}
\end{array}\right) & =\left(\begin{array}{ll}
\mathrm{H}_{11} & \mathrm{H}_{12} \\
\mathrm{H}_{21} & \mathrm{H}_{22}
\end{array}\right)\left(\begin{array}{l}
\varphi_{1} \\
\varphi_{2}
\end{array}\right) \\
\mathrm{W} & =\left[\begin{array}{ll}
\frac{-1+\mathrm{H}_{11}-\mathrm{H}_{22}+\Delta \mathrm{H}}{2 \mathrm{H}_{21}} & \frac{-1+\mathrm{H}_{11}+\mathrm{H}_{22}-\Delta \mathrm{H}}{2 \mathrm{H}_{21}} \\
\frac{1+\mathrm{H}_{11}+\mathrm{H}_{22}+\Delta \mathrm{H}}{2 \mathrm{H}_{21}} & \frac{1+\mathrm{H}_{11}-\mathrm{H}_{22}-\Delta \mathrm{H}}{2 \mathrm{H}_{21}}
\end{array}\right]
\end{aligned}
$$

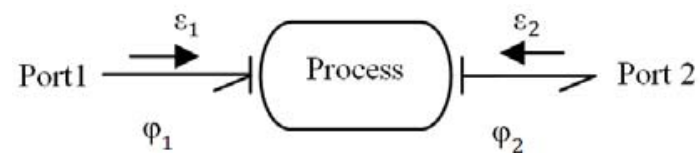

Fig. 7: Reduced bond graph model with effort-effort causality

Case 4: (Effort-effort causality): From Fig. 7 and by referring to Eq. 13, 16 and 17, we can deduce the following integro-differential operators and the corresponding wave matrix:

$$
\begin{aligned}
\left(\begin{array}{l}
\varphi_{1} \\
\varphi_{2}
\end{array}\right) & =\left(\begin{array}{ll}
\mathrm{H}_{11} & \mathrm{H}_{12} \\
\mathrm{H}_{21} & \mathrm{H}_{22}
\end{array}\right)\left(\begin{array}{l}
\varepsilon_{1} \\
\varepsilon_{2}
\end{array}\right) \\
\mathrm{W} & =\left[\begin{array}{ll}
\frac{-1+\mathrm{H}_{11}-\mathrm{H}_{22}+\Delta \mathrm{H}}{2 \mathrm{H}_{21}} & \frac{1-\mathrm{H}_{11}-\mathrm{H}_{22}+\Delta \mathrm{H}}{2 \mathrm{H}_{21}} \\
\frac{-1-\mathrm{H}_{11}-\mathrm{H}_{22}-\Delta \mathrm{H}}{2 \mathrm{H}_{21}} & \frac{1+\mathrm{H}_{11}-\mathrm{H}_{22}-\Delta \mathrm{H}}{2 \mathrm{H}_{21}}
\end{array}\right]
\end{aligned}
$$

Now, if we like to find the scattering matrix we need to use the Eq. 13.

We note that $\mathrm{H}_{\mathrm{ij}}$ are the integro-differentials operators which are based, in their determination, on the causal ways and algebraic loops present in the associated bond graph model (Maher and Scavarda, 1991).

$$
\begin{aligned}
& \mathrm{H}_{\mathrm{ij}}=\sum_{\mathrm{k}=1}^{\mathrm{N}} \frac{\mathrm{G}_{\mathrm{k}} \Delta_{\mathrm{k}}}{\Delta} \\
& \Delta=1-\sum \mathrm{L}_{\mathrm{i}}+\sum \mathrm{L}_{\mathrm{i}} \mathrm{L}_{\mathrm{j}}-\sum \mathrm{L}_{\mathrm{i}} \mathrm{L}_{\mathrm{j}} \mathrm{L}_{\mathrm{k}}+\ldots+(-1)^{\mathrm{m}} \sum \ldots+\ldots
\end{aligned}
$$

Where:

$$
\begin{aligned}
\Delta & =\text { the determinant of the causal bond graph } \\
\mathrm{H}_{\mathrm{ij}} & =\text { Complete gain between } \mathrm{P}_{\mathrm{j}} \text { and } \mathrm{P}_{\mathrm{i}} \\
\mathrm{P}_{\mathrm{i}} & =\text { Input port } \\
\mathrm{P}_{\mathrm{j}} & =\text { Output port } \\
\mathrm{N} & =\text { Total number of forward paths between } \mathrm{P}_{\mathrm{i}} \\
& \text { and } \mathrm{P}_{\mathrm{j}} \\
\mathrm{G}_{\mathrm{k}} \quad= & \text { Gain of the } \mathrm{k}^{\text {th }} \text { forward path between } \mathrm{P}_{\mathrm{i}} \text { and } \\
& \mathrm{P}_{\mathrm{j}} \\
\mathrm{L} & =\begin{array}{l}
\text { Loop gain of each causal algebraic loop in } \\
\text { the bond graph model }
\end{array} \\
\mathrm{L}_{\mathrm{i}} \mathrm{L}_{\mathrm{j}} \quad= & \begin{array}{l}
\text { Product of the loop gains of any two non- } \\
\text { touching loops (no common causal bond) }
\end{array} \\
\mathrm{L}_{\mathrm{i}} \mathrm{L}_{\mathrm{j}} \mathrm{L}_{\mathrm{k}}= & \begin{array}{l}
\text { product of the loop gains of any three } \\
\text { pairwise nontouching loops }
\end{array} \\
\Delta_{\mathrm{k}}= & \text { The cofactor value of } \Delta \text { for the } \mathrm{k}^{\text {th }} \text { forward } \\
& \text { path, with the loops touching the } \mathrm{k}^{\text {th }} \text { forward } \\
& \text { path removed; i.e., Remove those parts of }
\end{aligned}
$$


the causal bond graph which form the loop, while retaining the parts needed for the forward path

\section{MATERIALS AND METHODS}

Application to high frequency filter: In this paragraph, we will try to apply the new derivation or extraction method described previously to a high frequency filter with cut-off frequency $10 \mathrm{GHz}$, based on localized elements and connected between two ports noted Term 1 and Term 2 like Fig. 8 indicates it.

The causal bond graph model of this studied filter is given in Fig. 9.

Derivation of the scattering parameters from its bond graph model: To extract the scattering parameters from the bond graph representation and by using the new method this is described previously; we must transform the bond graph model into a causal bond graph model often named reduced bond graph model (Taghouti and Mami, 2009; Maher and Scavarda, 1991) only containing the decomposition junction (1-jonction or 0 -jonction) and the reduced variables with respect to a scaling resistance $R_{0}$ (internal source resistance).

We noted that:

- $z_{\mathrm{i}}$ : The reduced equivalent impedance of the $\mathrm{i}$ element put in series

- $\mathrm{y}_{\mathrm{i}}$ : The reduced equivalent admittance of the $\mathrm{i}$ element put in parallel

So we have:

$$
\begin{aligned}
& \mathrm{z}_{1}=\tau_{\mathrm{L} 1} * \mathrm{P} \\
& \mathrm{z}_{2}=\tau_{\mathrm{L} 2} * \mathrm{P} \\
& \mathrm{y}_{1}=\tau_{\mathrm{cl}} * \mathrm{P} \\
& \mathrm{y}_{2}=\tau_{\mathrm{c} 2} * \mathrm{P}
\end{aligned}
$$

p: The Laplace operator.

With:

$$
\begin{gathered}
\tau_{\mathrm{ci}}=\mathrm{R}_{0} * \mathrm{C}_{\mathrm{i}} \\
\tau_{\mathrm{Li}}=\frac{\mathrm{L}_{\mathrm{i}}}{\mathrm{R}_{0}}
\end{gathered}
$$

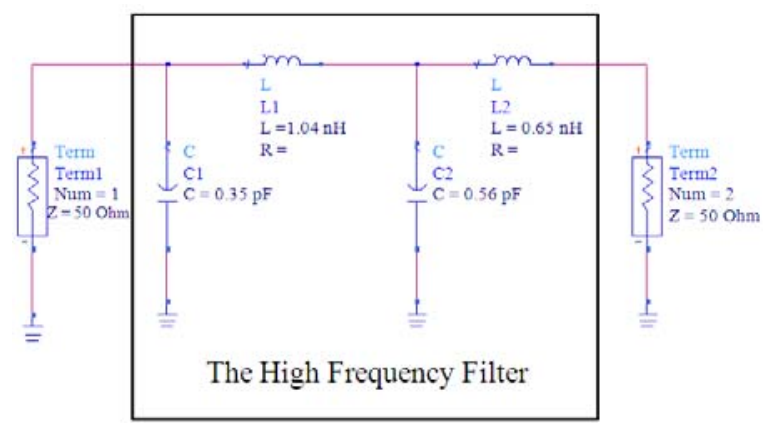

Fig. 8: High frequency filter representation and its ends term 1 and term 2

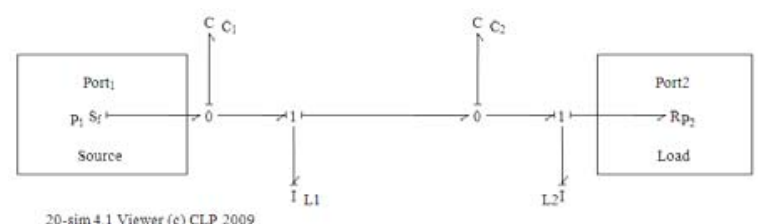

Fig. 9: Causal bond graph representation

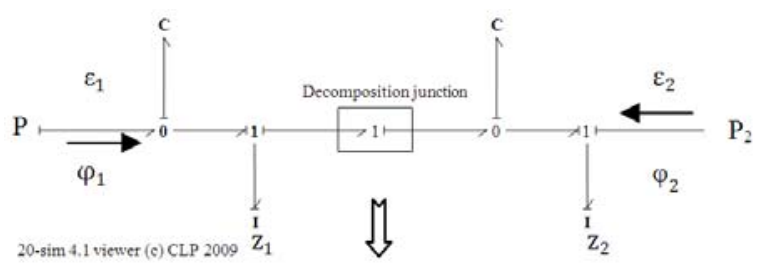

By decomposition :<smiles>[C]=[C]</smiles>

(a)
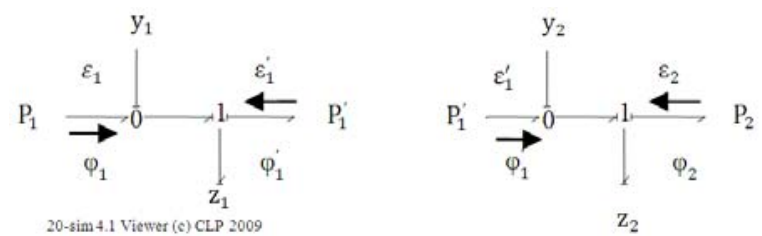

(b)

Fig. 10: (a): The reduced and transformed bond graph model (b): The tow bond graph sub-model

The tow sub-models given by Fig. 10a and $11 \mathrm{~b}$ are in conformity with case 1 described previously. So we have the integro-differentials operators by taking account to the previously equations:

$\mathrm{L}_{1}=\frac{-1}{\mathrm{z}_{1} \mathrm{y}_{1}} \quad=$ Loop gain of the algebraic loop given by the first sub-model 
Am. J. Applied Sci., 7 (5): 702-710, 2010

$\mathrm{L}_{2}=\frac{-1}{\mathrm{z}_{2} \mathrm{y}_{2}} \quad=$ Loop gain of the algebraic loop given by the second sub-model

$\Delta=1+\frac{1}{z_{1} y_{1}}=$ Determinant of causal bond graph of the first sub-model

$\Delta=1+\frac{1}{\mathrm{z}_{2} \mathrm{y}_{2}} \quad=$ Determinant of causal bond graph of the second sub-model

$\left\{\begin{array}{l}\mathrm{H}_{11}=\frac{\mathrm{z}_{1}}{\mathrm{z}_{1} \mathrm{y}_{1}+1} \\ \mathrm{H}_{12}=\frac{1}{\mathrm{z}_{1} \mathrm{y}_{1}+1} \\ \mathrm{H}_{21}=\frac{1}{\mathrm{z}_{1} \mathrm{y}_{1}+1} \\ \mathrm{H}_{22}=\frac{-\mathrm{y}_{1}}{\mathrm{z}_{1} \mathrm{y}_{1}+1} \\ \Delta \mathrm{H}=\frac{-1}{\mathrm{z}_{1} \mathrm{y}_{1}+1}\end{array}\right.$

The all integro-differentials operators of the first sub-model:

$$
\left\{\begin{array}{l}
\mathrm{H}_{11}=\frac{\mathrm{z}_{2}}{\mathrm{z}_{2} \mathrm{y}_{2}+1} \\
\mathrm{H}_{12}=\frac{1}{\mathrm{z}_{2} \mathrm{y}_{2}+1} \\
\mathrm{H}_{21}=\frac{1}{\mathrm{z}_{2} \mathrm{y}_{2}+1} \\
\mathrm{H}_{22}=\frac{-\mathrm{y}_{2}}{\mathrm{z}_{2} \mathrm{y}_{2}+1} \\
\Delta \mathrm{H}=\frac{-1}{\mathrm{z}_{2} \mathrm{y}_{2}+1}
\end{array}\right.
$$

The all integro-differentials operators the second sub-model.

From these operators, we can deduce directly the wave matrix of the first and second sub-model by taking account to equations of case 1 :

$$
\begin{aligned}
\mathrm{W}^{(1)} & =\frac{1}{2}\left[\begin{array}{cc}
\mathrm{z}_{1} \mathrm{y}_{1}-\mathrm{z}_{1}-\mathrm{y}_{1}+2 & -\mathrm{z}_{1} \mathrm{y}_{1}+\mathrm{z}_{1}+\mathrm{y}_{1} \\
-\mathrm{z}_{1} \mathrm{y}_{1}-\mathrm{z}_{1}+\mathrm{y}_{1} & \mathrm{z}_{1} \mathrm{y}_{1}+\mathrm{z}_{1}+\mathrm{y}_{1}
\end{array}\right] \\
\mathrm{W}^{(2)} & =\frac{1}{2}\left[\begin{array}{cc}
\mathrm{z}_{2} \mathrm{y}_{2}-\mathrm{z}_{2}-\mathrm{y}_{2}+2 & -\mathrm{z}_{2} \mathrm{y}_{2}+\mathrm{z}_{2}+\mathrm{y}_{2} \\
-\mathrm{z}_{2} \mathrm{y}_{2}-\mathrm{z}_{2}+\mathrm{y}_{2} & \mathrm{z}_{2} \mathrm{y}_{2}+\mathrm{z}_{2}+\mathrm{y}_{2}
\end{array}\right]
\end{aligned}
$$

The total wave matrix is given by the product of the first and the second wave matrix such us:

$$
\mathrm{W}^{(\mathrm{T})}=\mathrm{W}^{(1)} * \mathrm{~W}^{(2)}=\left[\begin{array}{ll}
\mathrm{W}_{11} & \mathrm{~W}_{12} \\
\mathrm{~W}_{21} & \mathrm{~W}_{22}
\end{array}\right]
$$
below:

So the corresponding scattering matrix is given $\mathrm{S}^{(\mathrm{T})}=\left[\begin{array}{cc}\mathrm{W}_{22}^{-1} * \mathrm{~W}_{12} & \mathrm{~W}_{11}-\mathrm{W}_{21} * \mathrm{~W}_{12} * \mathrm{~W}_{22}^{-1} \\ \mathrm{~W}_{22}^{-1} & -\mathrm{W}_{21} * \mathrm{~W}_{22}^{-1}\end{array}\right]$

From this matrix we can deduce these following scattering parameters:

$$
\begin{aligned}
& \mathrm{S}_{11} \frac{\mathrm{z}_{1} \mathrm{z}_{2} \mathrm{y}_{1} \mathrm{y}_{2}+\mathrm{z}_{1} \mathrm{y}_{2}\left(\mathrm{y}_{1}-\mathrm{z}_{2}\right)+\mathrm{z}_{1}\left(\mathrm{y}_{1}-\mathrm{y}_{2}-1\right)+}{\mathrm{z}(\mathrm{p})} \\
& \mathrm{S}_{12}=\mathrm{S}_{21}=\frac{2}{\mathrm{~d}(\mathrm{p})} \\
& \mathrm{S}_{22} \frac{\left.-\mathrm{y}_{2}-1\right)+\mathrm{y}_{1}+\mathrm{y}_{2}}{-\mathrm{z}_{1} \mathrm{z}_{2} \mathrm{y}_{1} \mathrm{y}_{2}+\mathrm{z}_{1} \mathrm{y}_{2}\left(\mathrm{y}_{1}-\mathrm{z}_{2}\right)+\mathrm{z}_{1}\left(\mathrm{y}_{2}-\mathrm{y}_{1}-1\right)} \\
& \mathrm{d}(\mathrm{z})=\mathrm{z}_{2}\left(\mathrm{y}_{1}+\mathrm{y}_{2}-1\right)+\mathrm{y}_{1}+\mathrm{y}_{2} \\
& \mathrm{~d}(\mathrm{p}) \\
& +\left(\mathrm{z}_{1}+\mathrm{z}_{2} \mathrm{y}_{1} \mathrm{y}_{2}+\mathrm{z}_{1} \mathrm{y}_{2}\left(\mathrm{y}_{1}+\mathrm{z}_{2}\right)+\left(\mathrm{y}_{1}+\mathrm{y}_{2}\right)+2\right.
\end{aligned}
$$

\section{RESULTS}

Thus, the validation is carried out by simulate the scattering parameters of equation 37,38 and 39 .

A simple programming of the following scattering parameters equations, give the Fig. 11-14 which represent respectively the reflexion and transmission coefficients of the studied filter.

$$
\begin{gathered}
\tau_{\mathrm{C} 1} \tau_{\mathrm{C} 2} \tau_{\mathrm{L} 1} \tau_{\mathrm{L} 2} \mathrm{p}^{4}+\tau_{\mathrm{L} 1} \tau_{\mathrm{C} 2}\left(\tau_{\mathrm{C} 1}-\tau_{\mathrm{L} 2}\right) \mathrm{p}^{3}+ \\
{\left[\tau_{\mathrm{C} 1}\left(\tau_{\mathrm{L} 2}+\tau_{\mathrm{L} 1}\right)+\tau_{\mathrm{C} 2}\left(\tau_{\mathrm{L} 2}-\tau_{\mathrm{L} 1}\right)\right] \mathrm{p}^{2}} \\
\mathrm{~S}_{11}=\frac{+\left(\tau_{\mathrm{C} 1}+\tau_{\mathrm{C} 2}-\tau_{\mathrm{L} 1}-\tau_{\mathrm{L} 2}\right) \mathrm{p}}{\tau_{\mathrm{C} 1} \tau_{\mathrm{C} 2} \tau_{\mathrm{L} 1} \tau_{\mathrm{L} 2} \mathrm{p}^{4}+\tau_{\mathrm{L} 1} \tau_{\mathrm{C} 2}\left(\tau_{\mathrm{C} 1}+\tau_{\mathrm{L} 2}\right) \mathrm{p}^{3}+} \\
\left(\tau_{\mathrm{C} 1}+\tau_{\mathrm{C} 2}\right)\left(\tau_{\mathrm{L} 1}+\tau_{\mathrm{L} 2}\right) \mathrm{p}^{2}+ \\
\left(\tau_{\mathrm{C} 1}+\tau_{\mathrm{C} 2}+\tau_{\mathrm{L} 1}+\tau_{\mathrm{L} 2}\right) \mathrm{p}+2 \\
-\tau_{\mathrm{C} 1} \tau_{\mathrm{C} 2} \tau_{\mathrm{L} 1} \tau_{\mathrm{L} 2} \tau_{\mathrm{C} 2} \mathrm{P}^{4}+\tau_{\mathrm{L} 1} \tau_{\mathrm{C} 2}\left(\tau_{\mathrm{C} 1}-\tau_{\mathrm{L} 2}\right) \mathrm{p}^{3}+ \\
{\left[\tau_{\mathrm{C} 2}\left(\tau_{\mathrm{L} 1}+\tau_{\mathrm{L} 2}\right)-\tau_{\mathrm{C} 1}\left(\tau_{\mathrm{L} 1}+\tau_{\mathrm{L} 2}\right)\right] \mathrm{p}^{2}+} \\
\mathrm{S}_{22}=\frac{\left(\tau_{\mathrm{C} 1}+\tau_{\mathrm{C} 2}-\tau_{\mathrm{L} 1}-\tau_{\mathrm{L} 2}\right) \mathrm{p}}{\tau_{\mathrm{C} 1} \tau_{\mathrm{C} 2} \tau_{\mathrm{L} 1} \tau_{\mathrm{L} 2} \mathrm{p}^{4}+\tau_{\mathrm{L} 1} \tau_{\mathrm{C} 2}\left(\tau_{\mathrm{C} 1}+\tau_{\mathrm{L} 2}\right) \mathrm{p}^{3}+} \\
\left(\tau_{\mathrm{C} 1}+\tau_{\mathrm{C} 2}\right)\left(\tau_{\mathrm{L} 1}+\tau_{\mathrm{L} 2}\right) \mathrm{p}^{2}+ \\
\left(\tau_{\mathrm{C} 1}+\tau_{\mathrm{C} 2}+\tau_{\mathrm{L} 1}+\tau_{\mathrm{L} 2}\right) \mathrm{p}+2
\end{gathered}
$$




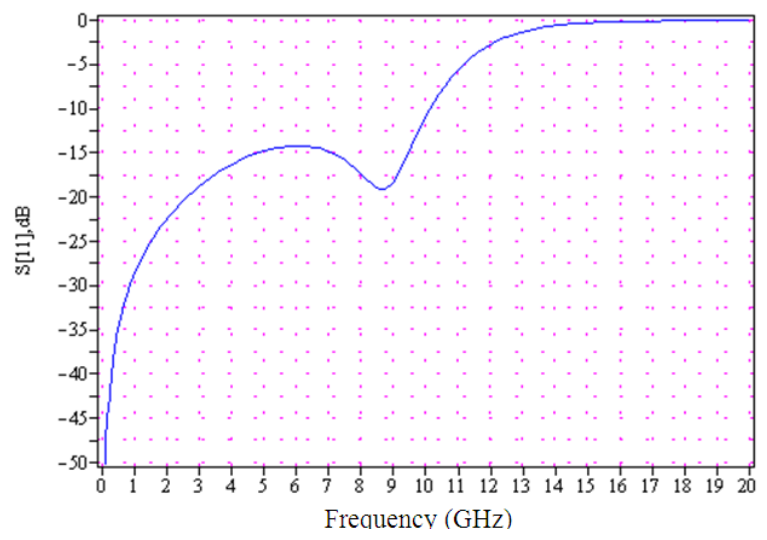

Fig. 11: Reflexion coefficient $S_{11}$ seen at entry

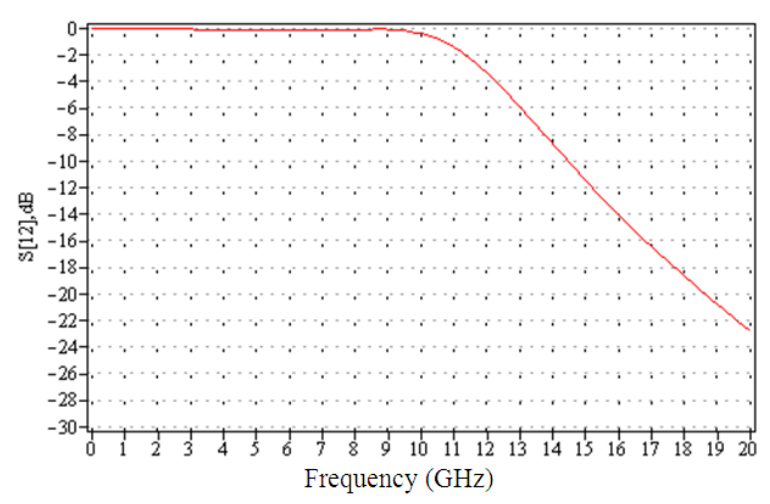

Fig. 12: Transmission coefficient $S_{12}$ seen from exit to entry

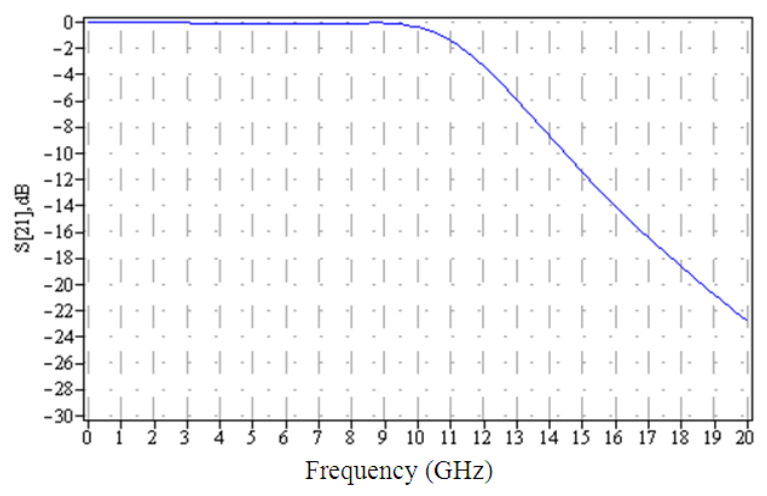

Fig. 13: Transmission coefficient $S_{21}$ seen from entry to exit

$$
\begin{aligned}
\mathrm{S}_{21}= & \frac{2}{\tau_{\mathrm{C} 1} \tau_{\mathrm{C} 2} \tau_{\mathrm{L} 1} \tau_{\mathrm{L} 2} \mathrm{p}^{4}+\tau_{\mathrm{L} 1} \tau_{\mathrm{C} 2}\left(\tau_{\mathrm{C} 1}+\tau_{\mathrm{L} 2}\right) \mathrm{p}^{3}+\left(\tau_{\mathrm{C} 1}+\tau_{\mathrm{C} 2}\right)} \\
& \left(\tau_{\mathrm{L} 1}+\tau_{\mathrm{L} 2}\right) \mathrm{p}^{2}+\left(\tau_{\mathrm{C} 1}+\tau_{\mathrm{C} 2}+\tau_{\mathrm{L} 1}+\tau_{\mathrm{L} 2}\right) \mathrm{p}+2
\end{aligned}
$$

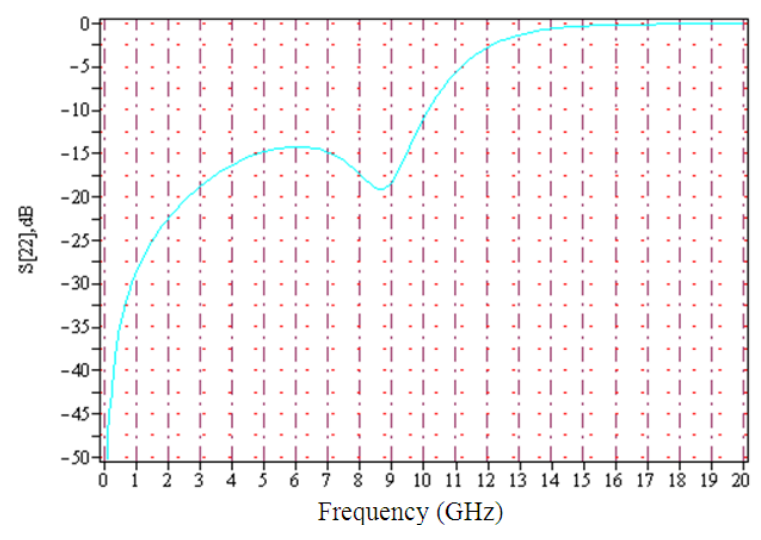

Fig. 14: Reflexion coefficient $\mathrm{S}_{22}$ seen at exit

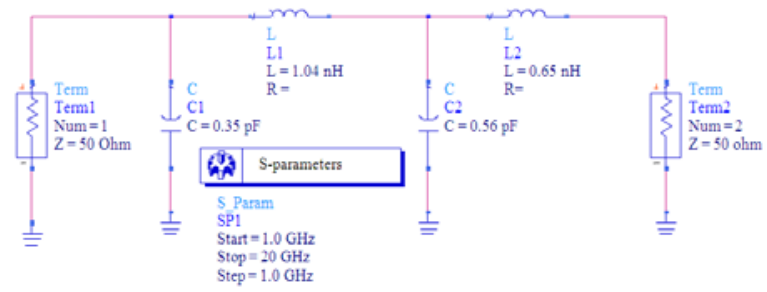

Fig. 15: The high frequency filter under HP-ADS software

$$
\begin{aligned}
\mathrm{S}_{21}= & \frac{2}{\tau_{\mathrm{C} 1} \tau_{\mathrm{C} 2} \tau_{\mathrm{L} 1} \tau_{\mathrm{L} 2} \mathrm{p}^{4}+\tau_{\mathrm{L} 1} \tau_{\mathrm{C} 2}\left(\tau_{\mathrm{C} 1}+\tau_{\mathrm{L} 2}\right) \mathrm{p}^{3}+\left(\tau_{\mathrm{Cl}}+\tau_{\mathrm{C} 2}\right)} \\
& \left(\tau_{\mathrm{L} 1}+\tau_{\mathrm{L} 2}\right) \mathrm{p}^{2}+\left(\tau_{\mathrm{C} 1}+\tau_{\mathrm{C} 2}+\tau_{\mathrm{L} 1}+\tau_{\mathrm{L} 2}\right) \mathrm{p}+2
\end{aligned}
$$

We notice that the reflex ions coefficients $S_{11}$ and $\mathrm{S}_{22}$ are equal in module. This result is also checked by the figures below:

$$
\left|\mathrm{S}_{11}\right|=\left|\mathrm{S}_{22}\right|
$$

To validate and checked the found results, by simulation, it is enough to simulate the high frequency filter of the Fig. 15 to find the representative curves of the reflexion and transmission coefficients respectively $S_{i i}$ and $S_{i j}$ under HP-ADS software (Advanced Design System) Dirk Jansen et al. (2003) often used in microwave and it is regarded as a traditional method in the line's theory (Magnusson et al., 2001)

The Fig. 15 thus represents the system's model studied with adapted entry and exit and the numerical values of its elements necessary for simulation.

The simulation of the high frequency filter above gives the graphical representation of the reflexion and transmission coefficients $S_{i i}$ and $S_{i j}(i \neq j$ and $i, j=1 \ldots 2)$ according to the frequency like Fig. 16 indicates it. 


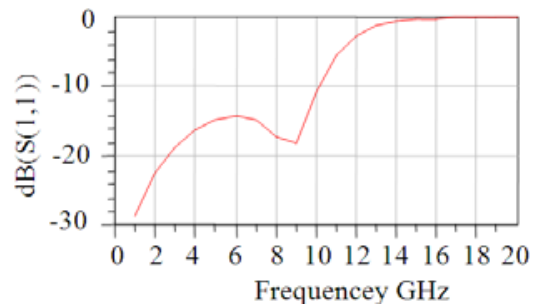

(a)

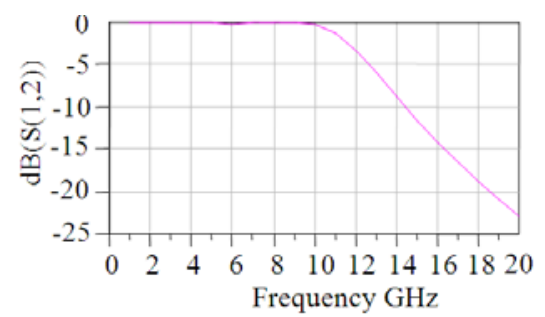

(b)

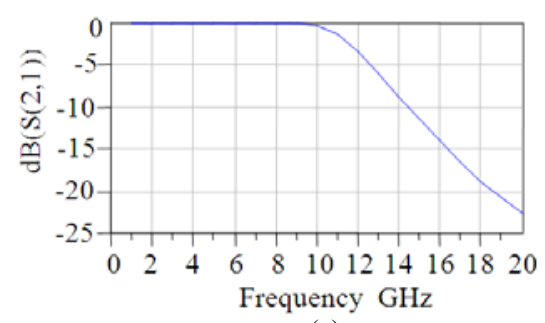

(c)

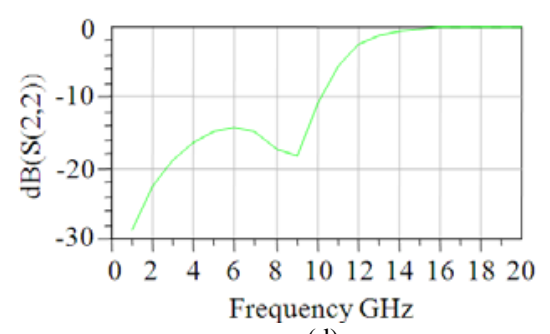

(d)

Fig. 16: Simulation results of the high frequency filter

\section{DISCUSSION}

The purpose of these simulations is to validate this new extraction method of scattering parameters from a causal bond graph model of a filter often functioning in high frequency and contrary to the work carried out by Kamel et al. (1993) and Kamel and Dauphin-Tanguy (1996) where the causality concept was ignored and which represents a significant property in the formalism with network type and in particular the bond graph formalism.

All simulation given by Fig. 11-14 were carried out in the maple software they give us the curves of the reflexion coefficients $\left(\mathrm{S}_{11}\right.$ and $\left.\mathrm{S}_{22}\right)$ and transmission coefficients $\left(\mathrm{S}_{12}\right.$ and $\left.\mathrm{S}_{21}\right)$. These curves give us information about the cut-off frequency and the type of the studied filter which is a low-pass filter with cut-off frequency $10 \mathrm{GHz}$.

The second type of simulation which given by the Fig. 16 was carried out in the HP-ADS software to validate the simulation results given by the new extraction method.

The direct simulation of the studied filter under the HP-ADS software and the simulation by the new analytical method show that the tow representations are equivalent.

\section{CONCLUSION}

In this study, we showed how we can extract the scattering parameters (scattering matrix S) of any physical system by a jointly use of the scattering formalism and the bond graph technique and by taking account to the causality concept.

Indeed, by adopting the reticulation assumption which allows the phenomena separation and the orthogonality property of the scattering matrix $\mathrm{S}$ associated to a physical system, we showed the existence of an ideal structure junction of Kirchhoff which includes a junction with common effort and flow known as a decomposition junction (0-junction or 1junction: according to the studied system type).

We showed how to characterize the interaction between several systems by using the bond graph concepts such as the generalized variables effort, flow, impedance and admittance in order to give a physical interpretation of the various concepts introduced by the scattering formalism.

The new developed method and applied to a filter functioning in high frequency makes it possible, on the one hand, to obtain a scattering representation of complex systems and on the other hand to confirm that the scattering formalism has the same properties as the bond graph formalism and thus belonged to the formalism's class of network type.

In a future study, we'll use this new method which combines at the same time the bond graph technical and the scattering formalism for modeling and simulation of the scattering matrix of any physical system functioning in high or low frequency by building a special form of bond graph model often named "scattering bond graph model" which enable us to capture the power transfers in a simple and direct manner at the same time and it proposes us a temporal approach of the phenomena usually modeled with the frequencies tools. 


\section{ACKNOWLEDGMENT}

We would like to thank especially Prof. MAMI Abdelkader for the time and guidance given throughout the all carried out works, without forgetting the members of the unit of electronics and high frequency circuits and all those who contributed and aided for this study in particularly L.A.C.S members (Laboratory of analysis and commands systems).

\section{REFERENCES}

Cellier, F.E., 1995. Bond Graphs: The right choice for educating students in modeling continuous-time physical systems. Simulation, 64: 154-159. DOI: 10.1177/003754979506400303.

Di Filippo, J.M., M. Delgado, C. Brie and H.M. Paynter, 2002. A survey of bond graphs: Theory, applications and programs. J. Franklin Inst., 328: 565-606. DOI: 10.1016/00160032(91)90044-4.

Duclos, G. and A.H. Clement, 2003. A new method for the calculation of transmission and reflection coefficients for water waves in a small basin. Compt. Rendus. Mecanique., 331: 225-230. DOI: 10.1016/S1631-0721(03)00053-6.

Jansen, D., 2003. Advanced Design System: The Electronic Design Automation Handbook. 1st Edn., Springer, ISBN: 10: 1402075022, pp: 680.

Kamel, A. and G. Dauphin-Tanguy, 1996. Power transfer in physical systems using the scattering bond graph and a parametric identification approach. Syst. Anal. Modeling Simulation, 27: 1-13. http://portal.acm.org/citation.cfm?id=240821.240 824. ISSN:0232-9298.

Kamel, A., C. Sueur and G. Dauphin-Tanguy, 1993. How to derive a bond graph model from a transfer matrix. J. Franklin Inst., 330: 787-798. DOI: 10.1016/0016-0032(93)90077-8

Khachatryan, K.H. and K.H.A. Khachatryan, 2008. Factorization of a convolution-type integrodifferential equation on the positive half line. Springer Link, 60: 1823-1839. DOI: 10.1007/s11253-009-0172-6
Magnusson, P.C., A. Weisshaar, V.K. Tripathi and G.C. Alexander, 2001. Transmission Lines and Wave Propagation. 4th Edn., CRC Press, USA., ISBN: 0-8493-0269-2(alk. paper), pp: 519.

Maher, A. and S. Scavarda, 1991. A procedure to match bond graph and scattering formalisms. J. Franklin Inst., 328: 887-899. DOI: 10.1016/00160032(91)90060-G

Newton, R.G., 2002. Scattering Theory of Waves and Particles. Dover Edn., Springer-Verlag, New York, ISBN: 0-486-42535-5 (pbk.), pp: 768.

Paynter, H.M. and I.J. Busch-Vishniac, 1988. Wave scattering Approaches to conservation and causality. J. Franklin Inst., 325: 295-313. DOI: 10.1016/00160032(88)90442-5.

Paynter, H.M., 1992. An Epistemic Prehistory of Bond Graphs. In: Interesting Historic Perspective by the Inventor Himself, Breedveld, P.C. and G. DauphinTanguy (Eds.). Bond Graphs for Engineers, Elsevier, Amsterdam, pp: 3-17.

Taghouti, H. and A. Mami, 2009. Application of the reduced bond graph approaches to determinate the scattering parameters of a high frequency filter. Proceeding of the 10th International Conference on Sciences and Techniques of Automatic Control and Computer Engineering (STA'2009), Academic Publication Center Tunisia, 20-22 Dec. 2009, Hammamet Tunisia, pp: 379-391. http://www.statn.com/site/papiers/Conference_Pro gram_STA_2009.pdf

Trabelsi, H., A. Gharsallah and H. Baudrand, 2003. Analysis of microwave circuits including lumped elements based on the iterative method. Int. J. RF Microwave CAE., 13: 269-275. DOI: 10.1002/mmce. 10084 .

Vendelin, G.D., A.M. Pavio and U.L. Rohde, 2005. Microwave Circuit Design Using Linear and Non Linear Techniques. 2nd Edn., John Wiley and Sons, Inc., ISBN: 978-0-471-41479-7, pp: 1080. 